\title{
The Imagistic Turn in Education: Opportunities and Constraints $^{+}$
}

\author{
András Benedek \\ MTA-BME Open Content Development Research Group, Budapest University of Technology and \\ Economics, Magyar tudósok krt. 2., 1117 Budapest, Hungary; benedek.a@eik.bme.hu \\ + Presented at the International and Interdisciplinary Conference IMMAGINI? Image and Imagination \\ between Representation, Communication, Education and Psychology, Brixen, Italy, 27-28 November 2017.
}

Published: 21 November 2017

\begin{abstract}
My talk consists of three parts. First, I present the urges and antecedents that are present in the current development of the concept of visuality and can affect education as a considerable development potential. Almost half a century ago something started in education, creating a new learning environment inside and outside the walls of schools by turning static images into dynamic ones. Putting the phenomenon into a conceptional frame, Multimedia Content Development has set new questions and new responses. Owing to the mobile communication tools, Comenius' Orbis Pictus has become really visible everywhere and at all times in a physical as well as a theoreticalmethodological sense, changing by this our learning environment. Recognizing these tendencies, in the second part of my talk, I will deal with what I call the new education dilemmas. The core of these is that e-learning, which shapes everyday learning environments by "ubiquitous computing", more and more turns away from the traditional or dominant verbal communication, and searches for alternatives by means of which it can be more interesting and more effective for the users. Owing to this situation, serious challenges can be identified with respect to pedagogy. The spontaneous effects of the original human natural characteristics of visual thinking in learning can be considered as an important altering factor in the learning paradigm. The relevant philosophical framework has been there for almost half a century; by now, however, as a result of technological development, it is already generating innovation steps at the practical level. The third part of my talk points to the current search for ways and possibilities, offering not so many solutions, but rather specific examples of investigations and experiments. Instead of suggesting a rigid change of the paradigm I point to the perspective of simply the modalities becoming more complex. In teaching and learning, multimodality - as an attitude which is able to make learning more effective than ever before by means of applying images and signs and rendering the methods of communication significantly more complex - can probably be an important step made forward, leaving behind mechanical, and so rigid, didactical systems. In a modern pedagogical sense, it is highly interesting to examine the notion of modality in terms of teaching and learning in the new technological environment. In its everyday connotation, modality means manner; the speaker's relation to the coverage of the scope of reality. Considering the special information and knowledge transmitting moments of education, modality means the imparter's and the recipient's relation to the content or its coverage of reality. With its earlier centuries-long dominance, the traditional linguistic modality hid the visual modality. Interestingly, the notion of multimodality first appeared in transportation, and so in communication as well, like a "specific method of transportation", meaning a combined solution including several manners. In linguistic communication, multilingualism, too, means multimodality, and when we are referring to one of the great experiences of our era, i.e., the modality of sign language rich in visual and gestural elements, we are coming closer and closer to the realization that in today's learning it is precisely multimodal communication that makes us able to transmit knowledge effectively, especially in the cases of disadvantaged groups. In the wake of the 20th century, "modern" learning materials have remained unchanged in terms of verbal and image communication, linear structure, written text dominance, and static image conveyance.
\end{abstract}


Although electronic learning resources and multi-media e-learning representations include more dynamic (flash, podcast, video) transfers of content, the "logic" of building up learning materials has changed little-in fact, visual content is only a complement to verbal communication. But when it comes to community-based learning resource development, teacher training may offer outstandingly good conditions for visual learning.

Keywords: education; visual learning; multimodality; open content

\section{Introduction}

Image and imagination in education seem to me a symbolic turning point in the recent struggle to modernize education and to bring learning closer to the nature of man. The educational environment in one of the traditional European technical universities gave me a special multidisciplinary interest for studying image based technologies for teaching. The starting point was the topic of visuality in the framework of an interdisciplinary approach nearly a decade ago. Our philosophy-based discussions carried on with professor Kristóf Nyíri at that time about the role played by images in human activities inspired us to build on our ongoing research analysing the more and more complex effects of mobile communication tools on learning, and to establish the Visual Learning Lab [1] in the autumn of 2009 at the Budapest University of Technology and Economics in order to provide the possibility of a new scientific dialogue. We held workshops for those interested in the topic, arriving from various fields of scholarship and science. By today our series of regular meetings, introducing new research results has an eight-year history. The widest possible interpretation of visuality has attracted the interest of the representatives of several disciplines; the special program of the professional platform initiated by the philosopher and the education researcher was joined by professionals in linguistics, sociology and technical sciences from the very beginning.

International scientific interest and the recognition of the opportunity of dialogue led us to organize an international Visual Learning Conference each year since 2010; despite its modest measure-30-40 scientific papers - with talks by European and even overseas researchers, these conferences can contribute to the modern interpretation of visuality which is becoming more and more diverse even as a topic, as well as to the analysis of the complex developments implemented in various scenes of our life.

\section{Urges and Antecedents}

As to the education let me start with Rudolf Arnheim, who in the chapter "Vision in Education" of his fundamental work "Visual Thinking"[2] points out that photographs, drawings, models, or even the live demonstration, of the objects and connections to be studied, does not by itself guarantee a thoughtful grasp of the subject; merely the use of visual aids does just not provide a sufficiently favourable condition for visual thinking. The educator should not be content with paying lip service to the doctrine of visual aids, it is not enough to turn on the movie projector, more or less diffidently, to provide a few minutes of entertainment in the dark; what is needed is to acquire, and develop, a capacity to be able to discern the difference between a picture that makes its point and one that does not.

In our recent contradictional education world the challenge Arnheim drew attention to is, a great many decades later, and with a deluge of digital images, videos and animations surrounding, indeed invading, the learning environment, still very much with us. As my colleague, and co-editor on many occasions, Kristóf Nyíri claims: the "linguistic turn" much pre-dated the twentieth century, while of course the "iconic turn", too, has an age-old prehistory. There is an essential connection between the visual on the one hand, and the motor and the tactile on the other, as Arnheim recalls in his analysis of descriptive gestures, "those forerunners of line drawing" [3]. 
To cast a glance on historical background: more than three and the half centuries ago John Amos Comenius published a trilingual (Latin, German and Hungarian) edition of the Orbis Pictus, probably the most renowned and most widely circulated of school textbooks. It was the first historical step on the way forward to an imagistic turn in education as the first successful application of illustrations for teaching and learning by the first illustrated book for children [4].

After three and half centuries, visuality is today the most important keyword. Contemporary visual technology-film, video, interactive digital media-is promoting, but also demanding, radically new approaches to learning: the age of visual learning has begun. As we recently put it [5], in the beginning, was the image: the omnipresence of pictures. And what happens in education? How can we characterize the historical road from Comenius through a perhaps total dominance of text over picture through the rise of the image to contemporary educational theory? Does educational theory today possess the conceptual tools to understand the demands and vistas of visual thinking?

After the Millenium, a new vocabulary became formulated by the multimedia development trend, and there are new questions: Do educationalists by now have a clear idea of what genuine multimedia synthesis means? Do we have a grasp of true "multimedia logic" as contrasted merely to a motley of elements belonging to different media occurring in a common learning environment? We need new approaches to educational theory and practice in the visual age. And again new questions: How far have we progressed from the notion of "visual aids" to the idea of text-image integration?

By calling the images in question "visual", significant issues were raised by many thinkers. It was inspirational how Caroll formulated it: "... I wish to signal that these images are of the sort whose reference is recognized simply by looking, rather than by some process such as decoding or reading." [6]. Now to come to formal and nonformal learning in our general contemporary practice, the "learning space"-when being at educational institutes, or traveling, or staying at home, everywhere-looks similar to the physical behavior of light. Perhaps it is no coincidence that the teacher had long been seen as a "lantern". Stimulating visual learning tasks can be regarded as impulses, the influences of wich in the learning nets we have studied on a relatively large student population [7].

During the last decade, with new developments in technology - "Rethinking of Education" we stepped into a new phase [8]. After forty years Ferguson's ideas on the nonverbal thought in technology [9]), especially in a technical university environment, became extremely timely. I assume that the by application of new interactive techniques the learning space, particularly in the promotion of horizontal communication activities, will allow "bursts" to develop into durable "light". While stronger bursts of light are unambiguously related to visually dominant content and modes of communication, more mainstream, complex, content, and mode of presentation tend to have a more balanced influence. This recognition led me to make an initiative for a project of Open Content Development supported by the Hungarian Academy of Sciences. It is reasonable to investigate to what degree, and by means of what methods and techniques the intensity increase of learners' interest and the accompanying learning in a complex communication space can be sustained, furthermore how the outlined potential of networked learning can be utilized in the optimization training programs required by individuals and institutions alike.

In a modern pedagogical sense, it is highly interesting to examine the notion of modality in terms of teaching and learning in the new technological environment. In its everyday connotation, modality means manner; the speaker's relation to the coverage of the scope of reality. Considering the special information and knowledge transmitting moments of education, modality means the imparter's and the recipient's relation to the content or its coverage of reality. With its earlier centuries-long dominance, the traditional linguistic modality hid the visual modality. Interestingly, the notion of multimodality first appeared in transportation, and so in communication as well, like a "specific method of transportation", meaning a combined solution including several manners. In linguistic communication, multilingualism, too, means multimodality, and when we are referring to one of the great experiences of our era, i.e., the modality of sign language rich in visual and gestural elements, we are coming closer and closer to the realization that in today's learning it is precisely multimodal communication that makes us able to transmit knowledge effectively, especially in the cases of 
disadvantaged groups. All these connect to the development of visual thinking using visual metaphors that have become, exactly due to the spread of mobile communication tools, the dominant form of communication, and as a specific inverse of this, a potential method of learning for the young generations.

Metaphors have an essential role in our history. Researchers working on the cognitive linguistic paradigm focus on the characteristics of everyday language use related to conceptual thinking. A specific cognitive-visual metaphors research began with Forceville's survey on the surrealist paintings, in 1988. Research in multimodality is now a separate field of science, which includes methods of approaching communication theory based on cognitive linguistics and other paradigms. The notion of multimodal metaphor is often used to interpret everyday visual phenomena, usually analyzing everyday situations or advertisements. To go further, recently Forceville formulated a relevance theory of visual and multimodal information, where the "texts" to be discussed include logos, advertisements, cartoons, and comic panels [10].

To be more provocative: a remarkable study published in recent months has shown an essential asymmetrical relationship between verbal and visual thinking. The newest functional MRI surveys [11] stated that "Humans rely on at least two modes of thought: verbal (inner speech) and visual (imagery). Are these modes independent, or does engaging in one entail engaging in the other? To address this question, we performed a behavioral and an fMRI study. In the behavioral experiment, participants received a prompt and were asked to either silently generate a sentence or create a visual image in their mind."

We can assume that human thinking is primarily pictorial and only secondarily verbal. Millennia and centuries of literacy and book printing did not favor visual image mediation, but the digital medium makes the original visual dimension again a natural part of the human life. This lecture looks at the image from the point of view of the incentive of education, particularly its content and method. From a theoretical point of learning, it is easy to see that the picture is a much more suitable tool for transferring practical knowledge than just verbal communication. The picture not only captures a vision, shape, ancient or new knowledge in an unaltered position and content but is also a radical truth-carrier.

A series of new frameworks appeared in the digital learning environment and relevant new approaches are currently being formed. At the beginning in his essay Open Work [12] Eco half a century ago discussed the aesthetic properties of "open work" as essentially ambiguous, offering a range of potential meanings, where the author offers 'the interpreter, he performer, the addressee a work to be completed' [13] and by today it all became real. Today's modern e-learning curricula (OER-Open Education Resources) try to find the answer to the question how the curriculum can be "opened" and the knowledge transferred to students in an open structure. Professor Nyíri took a particularly inspiring role in finding such answers [14,15]. Joining his work and in the very framework of the above-mentioned VLL workshops and conferences, I took up the examination of questions related to educational construction $[16,17]$.

\section{New Educational Dilemmas}

At the turn of the millennium with the massive spread of mobile technologies, we are moving fast from the appearance of human-machine interactive communication to the formation of spatial independence of human communicational possibilities. These two landmarks implying new pedagogic challenges figuratively also symbolize thresholds, one of which we have already crossed, and hesitating at the other where we are faced with an ever complex transformation of the world of education. Our traditional approach to classroom teaching and learning fundamentally changed in the last decade by the possibility that visual aids-overhead projectors, video projectors-became virtualized, made real-time by broadband data transmission without physical presence. The development of ICT and e-learning are facilitated by "ubiquitous computing", where the technical and social features of the learning environment formed by virtual reality should always be considered. Distinct features of the new learning paradigm are interactivity, the manipulation of time 
and space and asynchronous learning. Obviously, this is less and less compatible with the traditions of formal education where teaching and learning are imprisoned in classrooms.

Open content development, which moves from the rigid system of central content development towards more dynamic content innovation where both teachers and students can participate through cooperative techniques, has a strong visual character. In the up-to-date info-communication technological (ICT) environment a new pedagogical opportunity appears: the Open Access principle and its adoption in a wider context of practice have stirred up pedagogical thinking, which means the trend of opening up education. According to these inputs and outputs, our network concept, which is characterized by active student contribution, encouraged the development of new educational content.

The results of these activities integrated the original OCD model to formulate a real open environment where information exchange is organized into an informal network. Following the definition of UNESCO: “... teaching, learning and research materials in any medium, digital or otherwise, that reside in the public domain or have been released under an open license that permits no-cost access, use, adaptation and redistribution by others with no or limited restrictions." There are several established OER databases which offer well distributed content development services and implementation sources.

Our pupils and young students who gain network knowledge in a variety of ways in today's ICT environment are not sufficiently motivated to learn and elaborate traditional learning materials. This finding is especially important as young people's communication practices, including communication amongst themselves, using the services offered by community applications (e.g., Facebook), reading news or blogs, etc., are dominated by image messages. While a basic element of the traditional classroom is the blackboard, where everyone can see the process of image making (writing and drawing), most of our educational materials include only few image elements. A practical reason for this, in addition to learning material design traditions that rely on text dominance, is the limited nature of students' books as well as the difficulties of handling images and colors in press work and its cost increasing the effect. Some students' books are indeed visually attractive, but this is rarely the case today given the differentiating nature of educational structures and the rapid changes of content.

The new multimodal environment represents new possibilities of education and demonstration such as learning based on playing, virtual worlds and the development of customized learning environments with permanently attached forms of communications such as thematic blogs and professional e-portfolios providing information on one's professional activities. At the same time, a look at the list of educational tools based on teachers' opinions since 2007 [18] clearly shows that YouTube has been in the lead in recent years, and the most popular forms of communication are software that allows the transmission and creative editing of image information (PowerPoint, Prezi, and Powtoon). So we can attach a particularly significant role to the motion picture, especially as animation-simulating an unknown future. In the context of the images, you can directly see what the world really is. Thus, the blind power of authority is replaced by the power of the visible world. In this new learning environment, social activity and methods based on social content development are basic attitudes. From an educational aspect, it is particularly important to note that in the web 2.0 space users develop contents together and share the knowledge thus created.

\section{Seeking Ways-Opportunities}

In the present framework, I would like to mention two examples relating to our R\&D activities seeking ways for improving education by images. First, the project Developing Open Education Resources (OER) with the participation of students means a potential of content and methodology that is capable of surpassing traditional, school and notebook based teaching. Secondly, a pilot curriculum development like the SYSBOOK [19] and the applied info-communication technology (ICT), open source and commercial learning management systems (LMS), memory independent management of complex visual elements and the flexible management of micro-contents. The OCD 
research concept is formed in conjunction with our activities at the Visual Learning Lab (VLL), set up in 2009 at the Budapest University of Technology and Economics (BME) [20].

The originally designed Sysbook represents the essence of system theory: different systems have a number of common basic properties which characterize their behavior. The main objective of the Sysbook was to introduce the basic notions of system theory and control engineering in a descriptive way easily comprehensible by anyone on one hand and more deeply through explanations and mathematical descriptions on the other. Our research deals with the questions of seeking a new teaching paradigm related to the idea, indeed the imagination. 'Systems and control are all around us'. During our endeavors to develop Open Education Resources (OER) within the frame work of our experiment implemented in 2015, we found that student participation offered great potentials in relation to the content and the methodology as well. The e-resource was created within the framework of a development which strived to surpass the usual forms of traditional learning materials and even their e-learning adaptions.

The SysBook has a special structure (Figures 1 and 2). Each of the almost 140 sections is of display size, each of them is built on six levels of interpretation (Comics-Description-Maths-ExampleTheoretical-Education). The content is presented in quantification units which the reader can read linearly but because of the levels of interpretation mentioned above, each unit offers a wide scope for getting to know the particular topic and examining it from various aspects. As a result of its structural features, SysBook takes the golden central position between modern hypertexts and traditional books. In the course of developing SysBook, it became a real demand to channel the students' work and their results into the process.

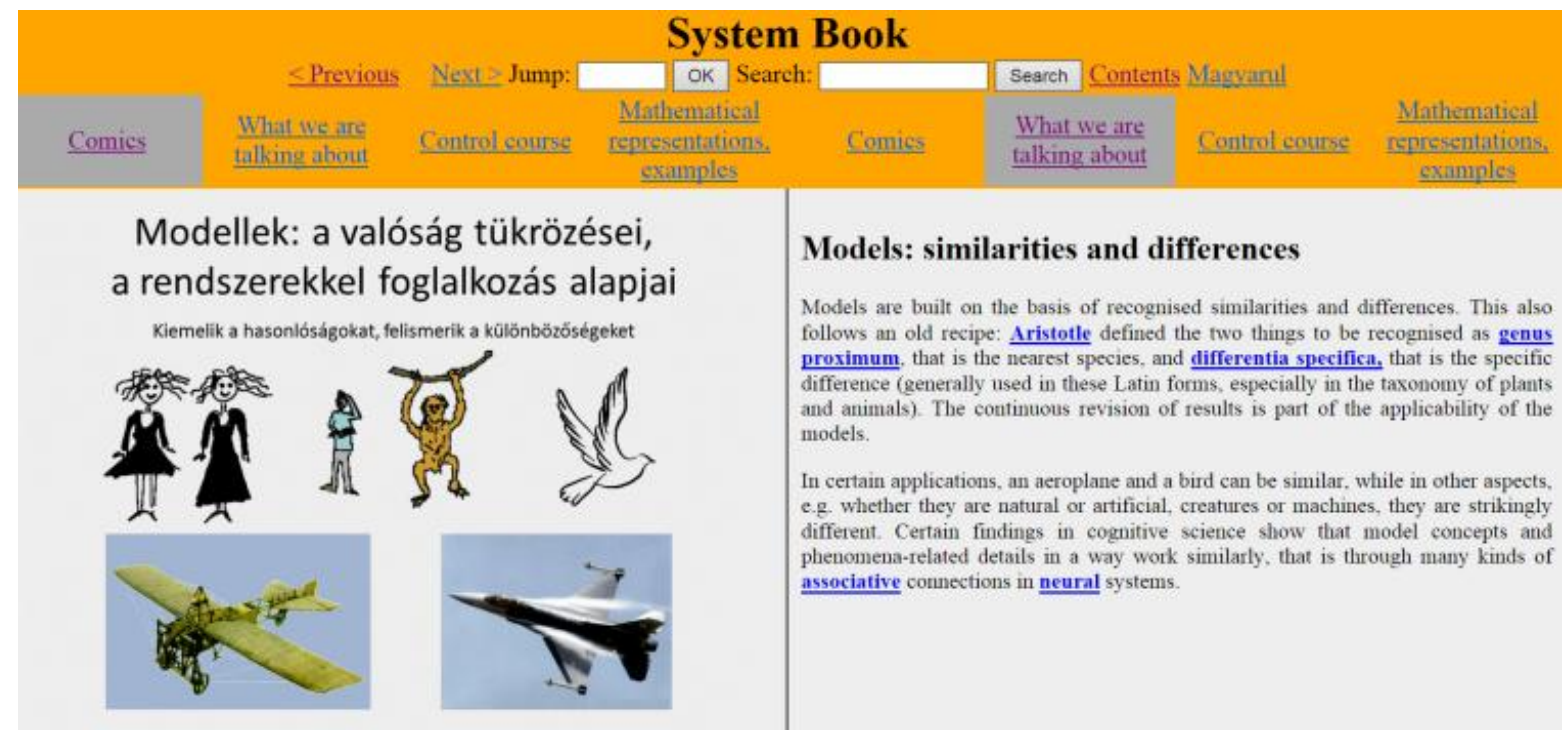

Figure 1. Illustration from SysBook-Models: similarities and differences [21]. 


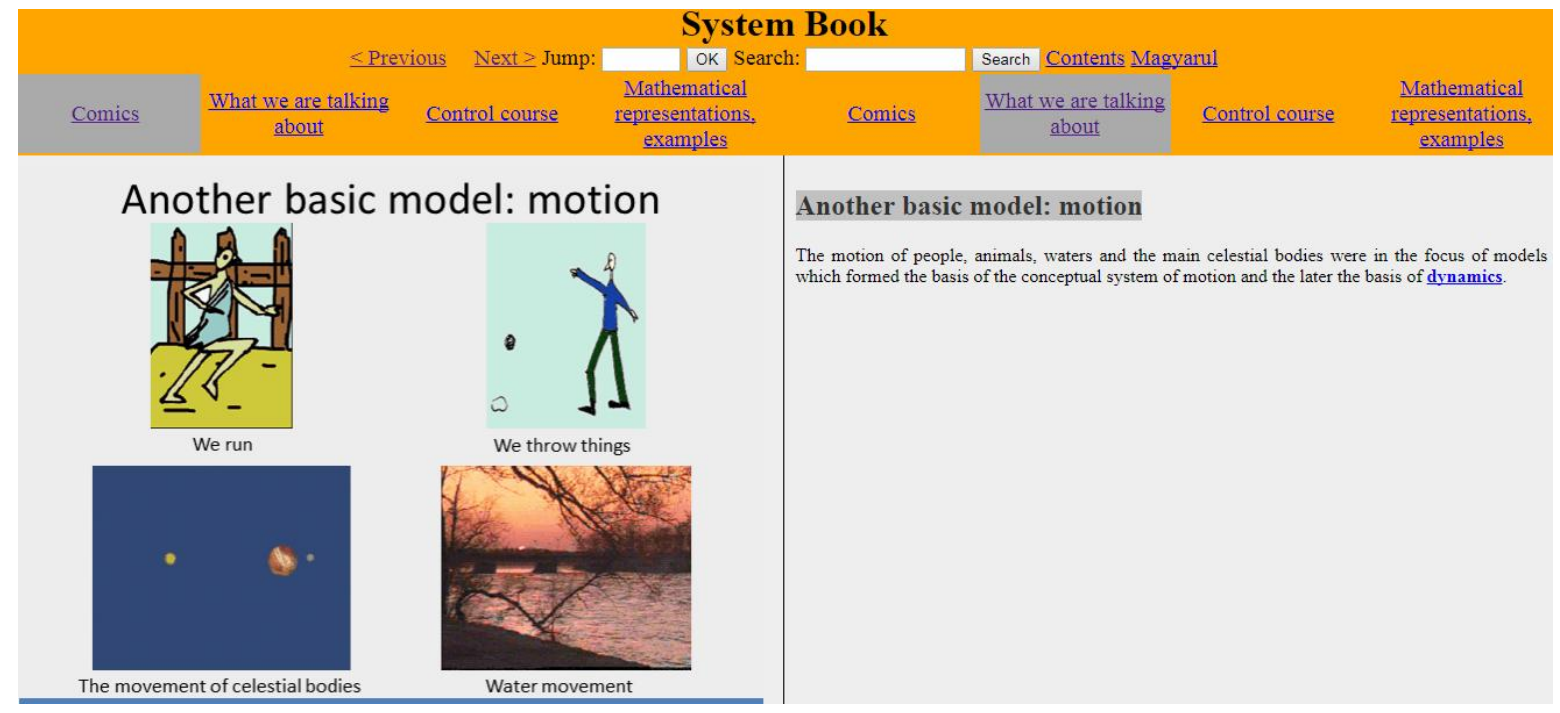

Figure 2. Illustration from SysBbook - Another basic model: motion [22].

The second example is based on our project at the Budapest University of Technology and Economics titled 'E-teaching Culture and Digital Content Development' and implemented between 2013 and 2015. It was aimed at developing content, methodologies, and services related to the competitiveness of higher education and the structural changes and at meeting the challenges of knowledge-based economies. Matching the peculiarities of higher education, we developed methodology training for complex subjects to develop the educational competences needed for designing and applying complex curriculum units in the training of teachers.

Our analyses proved that the measurable elements of learning activities show time-dependent characteristics that correlate with the visual communication forms and deadlines defined by study programs. From these results, we may conclude that the methods and techniques promoting the interest of the students in relation to the curricula and the development of learning activities are worth examining. In other words, it is worth studying how to utilize the potential hiding in network learning as such potentials are already perceived today, in the optimization of organic learning as demanded by individual learners and institutions.

Concerning methodological questions, with special regard to mathematics and other disciplines in natural sciences and the related applied sciences such as technical sciences and their applications, the curricula are based on descriptive verbal elements $($ Text $-t)$ that are supported by visual elements (Pictures $-\mathrm{V}$ ) and mathematical formulas (Math $-\mathrm{M}$ ) (see Figure 3). Traditional curricula (published in the format of textbooks) usually include the combination of these, structured in a rigid linear sequence, such as 'explanation, figures, formulation, explanation' and so on. In many cases, only random examples are given as case studies $(\mathrm{Case}-\mathrm{C})$ to illustrate practical applications. The visual representation illustrates the role of imagination as the most important feature of the structure as knowledge elements are organized into a system which is independent of scale. For curriculum design developed in open access, cloud services offer a development infrastructure surpassing all previous solutions. 


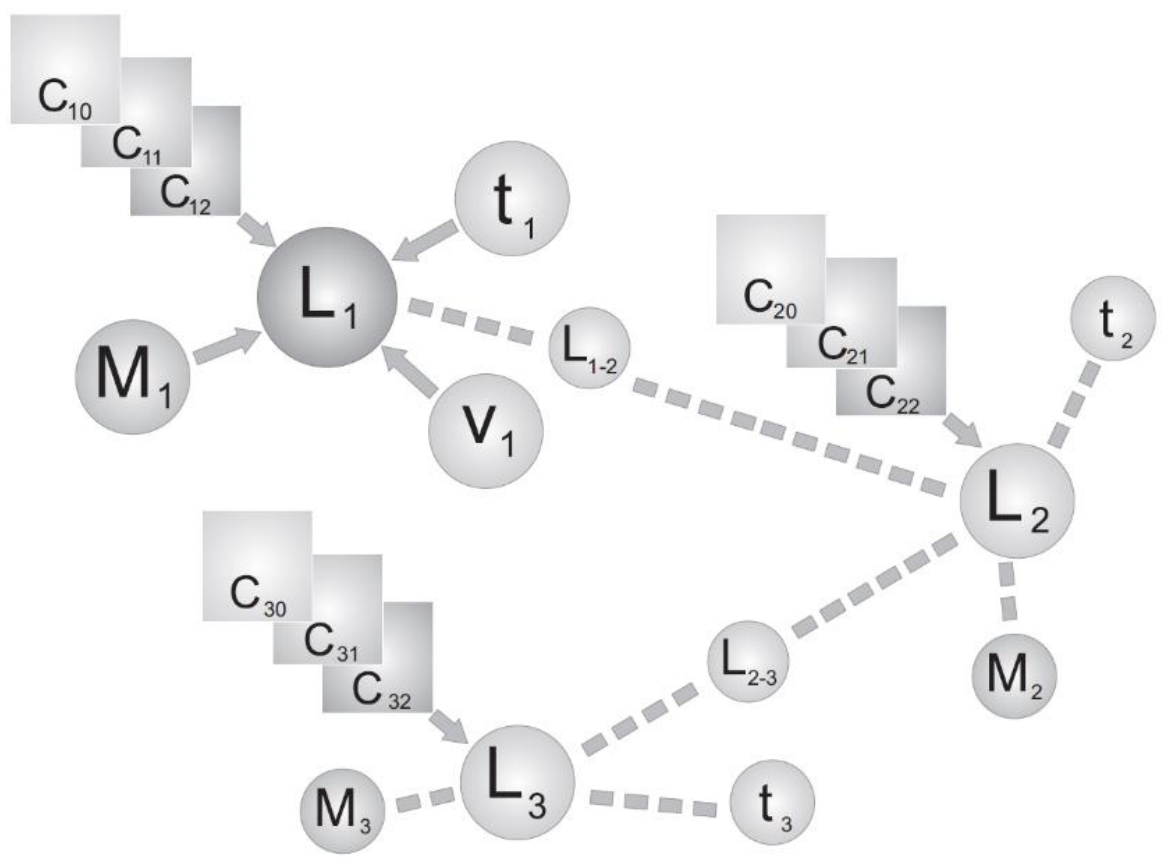

Figure 3. Connection of knowledge elements and the possibility of completion [23].

This new curriculum, where verbal and visual elements are presented in one-to-one ratio and where knowledge elements are organized into a network, would be scale-independent and structured as a graph; it would also be supported by a mathematical representation to enhance both its theoretical and practical aspects, and users would be allowed to extend it by means of case studies and practical examples.

\section{Conclusions}

In the wake of the 20th century, "modern" learning materials have remained unchanged in terms of verbal and image communication, linear structure, written text dominance, and static image conveyance. Although electronic learning resources and multi-media e-learning representations include more dynamic (flash, podcast, video) transfers of content, the "logic" of building up learning materials has changed little-in fact, visual content is only a complement to verbal communication. But when it comes to community-based learning resource development, teacher training may offer outstandingly good conditions for visual learning.

Concerning learning styles the new technologies are possibilities for focusing on personally used devices yet a constant strive for interactivity and networking. The learning network is not just an educational principle but also an environment where learning efficiently supports acquiring and continuously updating one's knowledge. Major current trends defining the interaction between education and its reflection in our imagination are the next:

- New forms of human-machine-human interaction by general use of mobile devices.

- The permanent communication in space and time mostly realized with pictures, icons, signs, images.

- The possibility to create complex, image based "learning environments" became really ramified and multimodal.

Conflicts of Interest: The author declares no conflicts of interest.

\section{References}

1. Available online: www.vll.bme.hu (accessed on 15 November 2017).

2. Arnheim, R. Visual Thinking; University of California Press: Berkeley, CA, USA, 1969. 
3. Arnheim, R. Art and Visual Perception: A Psychology of the Creative Eye; University of California Press: Berkeley, CA, USA, 1954.

4. Comenius, J.A. Orbis Sensualium Pictus Trilinguis Hoc est: Omnium Fundamentalium in Mundo Rerum, et in Vita Actionum, Pictura et Nomenclatura. Latina, Germanica et Hungarica. Cum Titulorum juxtá Atque Vocabulorum Indice = Die Sichtbare Welt Dinge, und Lebens Verrichtungen Vorbildung, und, Lateinische, Deutsche, und Ungarische Benamung. Samt Einen Titel- und Wörter-Register = A Látható Világ Háromféle Nyelven, az az: Minden Derekassab ez Világon Lévő Dolgoknak és ez Életben Való Tselekedeteknek le Ábrázolása és Deák, Német és Magyar Megnevezése. A Fellyúl Való Írásoknak és Szóknak Laystromával; Endterus: Noribergae (Nürnberg), Germany, 1669.

5. Benedek, A.; Veszelszki, Á. (Eds.) In the Beginning Was the Image: The Omnipresence of Pictures: Time, Truth, Tradition (Visual Learning); Series 6; Peter Lang: Frankfurt, Germany, 2016.

6. Caroll, N. Visual Metaphore. In Aspect of Metaphor; Jaako, H., Ed.; Kluwer Academic Publisher: Dordrecht, The Netherlands, 1994; pp. 189-218.

7. Benedek, A. A Pattern of Bursts or Constant Light. In The Iconic Turn in Education (Visual Learning); Series 2; Benedek, A., Nyíri, K., Eds.; Peter Lang: Frankfurt, Germany, 2012; pp. 39-49.

8. Collins, A.; Halverson, R. Rethinking Education in the Age of Technology; Teacher College Press: New York, NY, USA, 2009.

9. Ferguson, E.S. The mind's eye: Nonverbal thought in technology. Science 1977, 197, 827-836.

10. Forceville, C. Relevance Theory as model for analysing visual and multimodal communication. In Visual Communication; Machin, D., Ed.; De Gruyter Mouton: Berlin, Germany, 2014; pp. 51-70.

11. Amita, E.; Hoeflinc, C.; Hamzaha, N.; Fedorenko, E. An asymmetrical relationship between verbal and visual thinking: Converging evidence from behavior and fMRI. NeuroImage 2017, 152, 619-627.

12. Eco, U. Opera Aperta. Forma e Indeterminazione Nelle Poetiche Contemporanee; Bompiani: Milano, Italy, 1962.

13. Eco, U. The Open Work; Harvard University Press: Cambridge, MA, USA, 1989.

14. Nyíri, K. Elfelejtett képelméletek. In Képi Tanulás Műhelye Füzetek; Benedek, A., Nyíri, K., Eds.; 2016. Available online: https://www.academia.edu/29571702/Forgotten_Theories_of_the_Image_in_Hungarian_ (accessed on 15 November 2017)

15. Nyíri, K. Meaning and Motoricity: Essays on Image and Time; Peter Lang: Fankfurt, Germany, 2014.

16. Benedek, A. More Visual Content into Vocational Education. Opus Educ. 2015, 2, 39-47.

17. Benedek, A. Visual Education: Old and New Dilemmas. In The Power of the Image. Emotion, Expression, Explanation (Visual Learning); Benedek, A., Nyíri, K., Eds.; Peter Lang: Fankfurt, Germany, 2014; pp. 199-212.

18. Available online: http://c4lpt.co.uk/top100tools/ (accessed on 15 November 2017).

19. Sysbook. Available online: http://sysbook.sztaki.hu/sysbook6.php?lang=en (accessed on 15 November 2017).

20. Available online: http://www.ocd.bme.hu/en/main/ (accessed on 15 November 2017).

21. Available online: http://sysbook.sztaki.hu/sysbook6.php?page=12\&lang=en\&left=intro\&right=text (accessed on 15 November 2017).

22. Available: online: http://sysbook.sztaki.hu/sysbook6.php??14\&lang=en\&left=intro\&right=text (accessed on 15 November 2017).

23. Available online: http://www.ocd.bme.hu/en/about-the-project/ (accessed on 15 November 2017).

(C) 2017 by the authors. Licensee MDPI, Basel, Switzerland. This article is an open access article distributed under the terms and conditions of the Creative Commons Attribution (CC BY) license (http://creativecommons.org/licenses/by/4.0/). 